\title{
GLYCOPROTEIN ANALYSIS USING PROTEIN MICROARRAYS AND MASS SPECTROMETRY
}

\author{
Tasneem Patwa, ${ }^{1}$ Chen $\mathrm{Li}^{2}{ }^{2}$ Diane M. Simeone, ${ }^{3}$ and David M. Lubman ${ }^{2,4,5}$ * \\ ${ }^{1}$ Pfizer Global Research, Groton, CT \\ ${ }^{2}$ Department of Chemistry, University of Michigan, Ann Arbor, MI 48109 \\ ${ }^{3}$ Department of Surgery and Physiology, University of Michigan Medical \\ Center, Ann Arbor, MI \\ ${ }^{4}$ Department of Surgery, University of Michigan Medical Center, \\ Ann Arbor, MI \\ ${ }^{5}$ Comprehensive Cancer Center, University of Michigan, Ann Arbor, MI
}

Received 24 May 2009; received (revised) 28 July 2009; accepted 28 July 2009

Published online 13 January 2010 at wileyonlinelibrary.com. DOI 10.1002/mas.20269

Protein glycosylation plays an important role in a multitude of biological processes such as cell-cell recognition, growth, differentiation, and cell death. It has been shown that specific glycosylation changes are key in disease progression and can have diagnostic value for a variety of disease types such as cancer and inflammation. The complexity of carbohydrate structures and their derivatives makes their study a real challenge. Improving the isolation, separation, and characterization of carbohydrates and their glycoproteins is a subject of increasing scientific interest. With the development of new stationary phases and molecules that have affinity properties for glycoproteins, the isolation and separation of these compounds have advanced significantly. In addition to detection with mass spectrometry, the microarray platform has become an essential tool to characterize glycan structure and to study glycosylation-related biological interactions, by using probes as a means to interrogate the spotted or captured glycosylated molecules on the arrays. Furthermore, the highthroughput and reproducible nature of microarray platforms have been highlighted by its extensive applications in the field of biomarker validation, where a large number of samples must be analyzed multiple times. This review covers a brief survey of the other experimental methodologies that are currently being developed and used to study glycosylation and emphasizes methodologies that involve the use of microarray platforms. This review describes recent advances in several options of microarray platforms used in glycoprotein analysis, including glycoprotein arrays, glycan arrays, lectin arrays, and antibody/ lectin arrays. The translational use of these arrays in applications related to characterization of cells and biomarker discovery is also included. (C) 2010 Wiley Periodicals, Inc., Mass Spec Rev 29:830-844, 2010

Tasneem Patwa and Chen Li contributed equally to this work. Contract grant sponsor: National Institutes of Health (NIH); Contract grant number: R01GM4900; Contract grant sponsor: National Cancer Institute; Contract grant numbers: 1R21CA124441, R01 CA106402; Contract grant sponsor: NCI-EDRN under CA084986 under a sub contract from Johns Hopkins University.

*Correspondence to: David M. Lubman, University of Michigan Medical Center, 1150 West Medical Center Drive, Building MSRB1 Rm A510B, Ann Arbor, MI 48109-0656.

E-mail:dmlubman@umich.edu
Keywords: microarrays; biomarkers; glycoproteins; glycoarrays; lectins; antibody arrays; glycan arrays

\section{INTRODUCTION}

Carbohydrates are molecules that have the ability to exist in different isomeric forms that yield a variety of branching structures. The complex structures that result from building complex carbohydrates from simple sugars conjugate to a large range of biological molecules such as lipids, proteins, and cell surfaces which yield an array of biological selectivities. A glycan chain can extend from a protein surface for a specific interaction (Cyster, Shotton, \& Williams, 1991), and without site-specific glycosylations, many vital proteins would not be able to fold properly (Helenius \& Aebi, 2001). Glycosylated structures are involved in a range of events such as development, immune response, cell division, cancer cell camouflaging, pathogens homing in on host cells, injury, and inflammation. Gene products that participate in oligosacharride biosynthesis account for up to $1 \%$ of the translated genome. Of post-translational modifications (PTMs), only phosphorylation occurs to a similar magnitude as glycosylation. Glycosyltransferases and glycosidases in the endoplasmic reticulum and Golgi apparatus produce glycoproteins of highly targeted structures. The location and amount of sugar substitution is known to distinguish various cell types. For example, cancer cells have been shown to use abnormal glycosylation to evade detection by the immune system (Dennis et al., 1987; Codington \& Haavik, 1992). Acidity imparted to glycan structures through sialic acid residues at the termini of glycan structures also plays an important role in a glycoprotein's function. For example, the correct sialylation of $N$-linked branched structures is essential for the activity of tissue plasminogen activator (Geisow, 1992). Although glycosylation is an abundant PTM, analysis of the structural variation of glycan structures presents a challenging problem for analytical chemistry.

Many clinical biomarkers and therapeutic targets in cancer are glycoproteins (Ferretti et al., 2007; Levitt \& Slawin, 2007; Hogdall, 2008) such as CA125 in ovarian cancer, Her2/neu in breast cancer, and prostate-specific antigen (PSA) in prostate cancer. The alteration in protein glycosylation, which occurs 
through varying the heterogeneity of glycosylation sites or changing glycan structure of proteins on the cell surface and in body fluids, has been shown to correlate with the development and/or progression of cancer and other disease states (Arnold et al., 2008; Ohyama, 2008; Zhao et al., 2008; Meany et al., 2009). Identification of glycoprotein isoforms is becoming increasingly important to the diagnosis and management of human diseases, because several diseases result from glycan structural alterations such as I-cell disease and congenital disorders of glycosylation leukocyte adhesion deficiency type II (Kościelak, 1995). An opinion article by Lebrilla and An (2009) further details the potential of glycan markers for disease diagnosis. In this article, the authors stated that the future holds promise not only for disease diagnosis with glycan profiling but also to aid the clinician to better understand disease progression and disease strain identification.

The isolation and analysis of glycoproteins have followed a similar path as the study of proteins in general. The number of chromatographic and electrophoretic methods currently available has aided this work. Affinity chromatography has been of particular importance to allow the isolation of glycoproteins with the inherent affinity of glycan structures to lectins (Fang \& Zhang, 2008; Mechref, Madera, \& Novotny, 2008). However, the isolated proteins cannot be studied in their intact forms with conventional X-ray crystallography methods. Furthermore, isolated glycoproteins are often found as a mixture of different glycoforms that are difficult to resolve. If resolved, the glycoforms are present at very low levels that require highly sensitive detection technologies. A majority of studies have, therefore, focused on fragmenting the glycoprotein into glycopeptides or glycans and their corresponding proteins for further structural determination (Robbe, Michalski, \& Capon, 2006; Wuhrer et al., 2007; Zhao et al., 2007a; Dalpathado \& Desaire, 2008; Amon, Zamfir, \& Rizzi, 2008). Mass spectrometry and its continuous development have facilitated structural elucidation of these glycoproteins. The most important innovation has undoubtedly been the introduction of ESI and MALDI together with new types of mass analyzers that permit improved mass resolution and accuracy for more confident structural assignments.

Glycoproteins arise when proteins conjugate to various sugar chains (glycans) through amino acid residues. Linkage at asparagines results in $N$-linked glycoproteins, whereas linkage at serine or threonine results in $O$-linked glycoproteins. Although these two forms of glycosylation are the most prominent, other forms of glycosylation have been noted, such as glycation at lysine residues observed in diabetes (Rajeswari et al., 1991). $\mathrm{N}$-linked glycans contain $\mathrm{N}$-acetylglucosamine (GlcNAc) linked to asparagines via an amide bond. In $O$-glycans, $N$-acetylgalactosamine (GalNAc) links the oligosaccharide's reducing end to the hydroxyl of the serine or threonine residue in the protein. $N$-linked glycans possess a common core region of trimannosyl chitobiose with two or three antennas extending from it. $O$-linked glycans do not possess a core structure but comprise a number of different regions with common motifs.

The extent of glycosylation in a protein usually depends on the frequency of occurrence of asparagine, serine, and threonine residues. Furthermore, any potential glycosylation site might or might not be occupied with a variety of possible oligosacharride structures. With this complexity in mind, the following information would be required for the most comprehensive picture of the glycoproteome: all glycosylated structures, the carbohydrate sequence in these structures, the branching and linkage in each of these sequences, as well as the site of glycosylation.

This review presents some of the current methods for glycoprotein analysis, with a particular focus on a more recently developing technology, glycoprotein microarrays.

\section{CHROMATOGRAPHIC METHODS}

Chromatographic techniques have evolved considerably over the past years. Together with diverse sample preparation techniques, it is now possible to analyze a variety of sample types previously almost impossible to comprehend. Complex samples such as whole-cell proteins can now be enriched according to cellular organelles (Castle, 2004; Gauthier \& Lazure, 2008) or even classes of compounds (e.g., phosphoproteins or glycoproteins), to make it possible to zoom in on specific classes of molecules.

Lectin affinity chromatography is one such technique that has facilitated glycoprotein studies. Lectins are proteins that possess motifs that have a strong affinity for glycans (the sugar component of glycoproteins). This interaction is strong enough to exploit for isolation of glycoproteins. Many laboratories have successfully employed this technique to characterize glycoproteomes (Lotan, 1979; Hirabayashi \& Kasai, 2002; Hirabayashi, 2008a,b; Fang \& Zhang, 2008; Mechref, Madera, \& Novotny, 2008). Multi-lectin affinity chromatography (M-LAC), where columns containing stationary phases bound to different lectins with orthogonal affinities, have also been used in tandem to further separate enriched glycoproteins (Yang \& Hancock, 2005; Plavina et al., 2007; Dayarathna, Hancock, \& Hincapie, 2008). More recently, a high-performance M-LAC material (HP-MLAC) has also been published with improved throughput and recovery for glycoproteomics research (Kullolli, Hancock, \& Hincapie, 2008). Hydrophilic interaction chromatography (HILIC) and graphitized carbon-based reverse-phase chromatography have also been shown to profile glycan and glycopeptides at femtomole levels. Furthermore, the mobile phases in this technique are compatible with mass spectrometry (Wuhrer, de Boer, \& Deelder, 2009). However, enrichment and liquid chromatography alone do not provide all needed information relative to glycoproteomes, because the separated glycoproteins cannot be identified.

Mass spectrometry can be easily coupled to HPLC techniques as long as favorable solvent systems are being employed. This method has allowed very comprehensive and detailed structural characterization of glycoproteomes. However, an important factor to keep in mind in this case is that, to obtain $100 \%$ coverage with regard to protein structure, large quantities of protein are often needed, which might not be feasible when studying low-abundance proteins.

Two LC/MS-based approaches that have been employed to study glycoproteins include profiling glycans released from their glycoproteins and profiling glycopeptides from glycoprotein digests. In glycan mapping, all sugar moieties from the glycoprotein are first cleaved (typically using enzymatic reactions using PNGase F), isolated, and analyzed with 
HPLC-MS. Normal-phase HPLC is usually employed for separation due to the polar nature of the glycans being analyzed. This approach can provide valuable information about overall glycan structural changes that occur during disease progression as the phenotype of the cell changes (Zhao et al., 2007a). However, one pitfall of such a technique is that it does not provide information on the protein origin of the glycan.

Profiling of glycopeptides, in contrast, is a site-specific method. After enzymatic digestion of a glycoprotein with an endoprotease, the resulting mixture of glycosylated and unglycosylated peptides are analyzed with liquid chromatography and mass spectrometry. Due to the high degree of heterogeneity and the often high molecular weight of glycans, the mass spectral signals of glycopeptides are much weaker than those of unglycosylated peptides. Therefore, enrichment approaches are often required. Graphitized carbon, cellulose, sepharose, and lectins have been used as SPE materials for glycopeptide enrichment (Wada et al., 2007; Zhang, Go, \& Desaire, 2008). To optimize the number of assigned peaks in the mass spectra, a spectrum analysis and database search must be performed manually for each eluting fraction, except several wellcharacterized glycoproteins. If such an approach is employed to study two different samples, then the presence or absence of certain glycopeptide peaks can easily demonstrate differences between the two samples. Though glycan structures and binding sites of a glycoprotein can both be elucidated with glycopeptide profiling, this technique is lower throughput. A rapid method of analysis is still needed.

It is clear that solely LC-MS approaches to glycoprotein analysis, although very comprehensive, often prove difficult. Data analysis can become time consuming, and often a large amount of sample is required for complete characterization. Profiling complex mixtures of glycoproteins with the LC-MS method alone is particularly cumbersome and leads to loss of valuable information that is contained in lower abundance proteins that might never be detected with LC-MS approaches.

A technique that is becoming increasingly popular involves protein microarrays. Microarrays have proved to be a highthroughput technique because they allow multiple analytes to be investigated simultaneously due to their physical attachment to unique regions on a single microarray slide that can be analyzed with a reagent of choice (Tao, Chen, \& Zhu, 2007; Uttamchandani \& Yao, 2008; Voduc, Kenney, \& Nielsen, 2008). By taking advantage of the high-throughput nature of the microarray platform and exploiting the unique binding properties of glycoproteins, carbohydrates, and glycans, comprehensive studies of glycoproteomes are made possible. A variety of microarraybased platforms for the study of glycoproteins have been pursued thus far. Some of the platforms are discussed below.

\section{MICROARRAY PLATFORMS FOR GLYCOPROTEIN ANALYSIS}

\section{A. Carbohydrate Microarray}

Carbohydrate microarrays have become a standard tool for glycobiologists to screen large numbers of sugars and to determine the role of carbohydrates in biological systems (de Boer et al., 2007; Horlacher \& Seeberger, 2008; Laurent, Voglmeir, \& Flitsch, 2008; Park, Lee, \& Shin, 2008). The potential applications of carbohydrate arrays are shown in Figure 1. The carbohydrate can be either isolated from a natural source or can be chemically synthesized. The low quantity and the impurity of the isolated oligosaccharides limit their usage in a chip-format study, whereas now the use of synthesized glycans is dominating this field. A functional linker group required for immobilization of sugars on a glass surface can be readily incorporated in the synthesis process. A diversity of carbohydrate structures that resembles the whole mammalian glycome can be produced with fewer than 40 carbohydrate building blocks (Werz et al., 2007).

A variety of glycan-type structures are arrayed on multiple types of surface chemistries (e.g., nitrocellulose, glass, and dextran) after which they are screened for binding. The most general method for carbohydrate immobilization involves covalent attachment of chemically modified carbohydrates onto an $\mathrm{N}$-hydroxysuccinimide (NHS)- or epoxide-containing surface on a glass slide. Non-covalent, but site-specific, attachment of carbohydrates on underivatized surfaces is also possible. Interactions of different carbohydrate structures with a wide variety of biological targets, including proteins, RNA, viruses, and whole cells, have been investigated with this technique. This approach has been used to profile carbohydrate-binding proteins, the characterization of carbohydrate-cell recognition, as well as the detection of specific antibodies for the diagnosis of diseases (Dotan et al., 2006).

Glycan-microarray technology has been used to assess the virus-receptor specificity of influenza viruses based on the species-specific nature of the interaction between the virus and host glycans (Stevens et al., 2006). Recently, Ratner and Seeberger (2007) and Adams et al. (2004) have prepared carbohydrate slides to identify human immunodeficiency virus (HIV) vaccine candidate antigens, to detect pathogenic bacteria, and to determine the binding profile of heparin-binding proteins. With photogenerated glycan arrays, an immunogenic sugar moiety has been detected on the exosporium of anthrax spores for the development of a targeting vaccine (Wang et al., 2007). A neoglycolipid technology has been invented for microarray analysis of glycans (Feizi \& Childs, 1994; Feizi et al., 1994; Liu et al., 2007). The advantage of neoglycolipids is that they can be readily immobilized by hydrophobic force on the chemical surface. These glycans can react with lectins, anti-glycan monoclonal antibodies or carbohydrate-binding cytokines, or chemokines.

The utility of labeling methods for glycan array detection with fluorescence-tagged molecules has been limited by denaturation of protein and availability of secondary reagents. To overcome this problem, label-free detection techniques such as surface plasmon resonance (Nelson et al., 2001) and MALDI-TOF ( $\mathrm{Su}$ and Mrksich, 2002) have been used to monitor the protein-glycan interaction or carbohydrate-processing enzyme activity after the glycans are immobilized to a gold surface via the disulfide bond. In an application of using glycan array with MALDI-TOF-MS to study the GalTase-mediated galactosylation, mass spectra gave explicit information about the change of the sugar chain structure after glycan array 


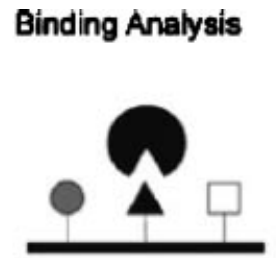

RNA Interactions

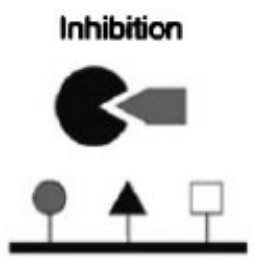

Antibody Screening

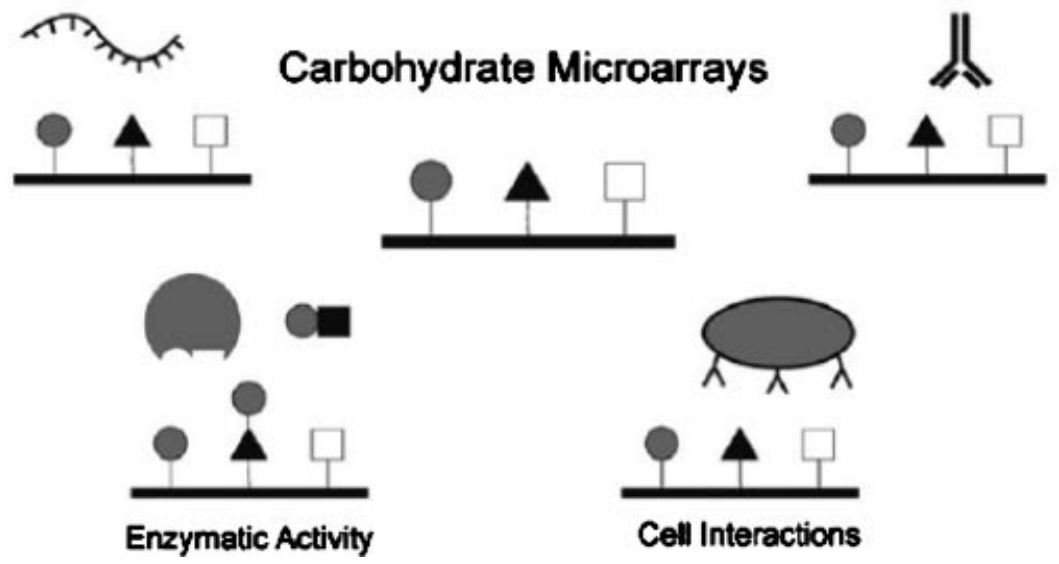

FIGURE 1. Application range of carbohydrate-microarray experiments. The carbohydrate-ligand specificity for carbohydrate-binding molecules has been assessed. Screening for inhibitors of carbohydrate-mediated interactions and determination of IC50 values can be performed by a co-incubation of the binding molecule with an inhibitor. Sugar interactions of an entire organism such as a whole cell or virus can be determined without purifying the carbohydrate-binding proteins. Reprinted and adapted with permission from Horlacher and Seeberger (2008). Copyright 2008, Royal Society Chemistry.

presenting $\beta$-GlcNAc were incubated with the enzyme ( $\mathrm{Su}$ and Mrksich, 2002).

\section{B. Lectin Arrays}

Although carbohydrate arrays yield valuable information about carbohydrate-interacting proteins, they do not allow one to directly examine changes in glycosylation. Alterations in carbohydrate structure of glycoproteins are known to be related to cellular regulation and tumor growth. Other technologies available for glycan analysis, such as chromatography and mass spectrometry, tend to be time consuming and less suitable for high-throughput evaluation of protein glycosylation. Although detailed information on glycan structures might be obtained with mass spectrometry, data analysis is complex and time consuming. The lectin array employs the same architecture as the glycan microarray (Fig. 2). There has been increased interest in the use of lectins in an array format (Nagaraj et al., 2008). Current studies with lectin arrays have focused on assessing the specificity of lectin binding to carbohydrates. Lectin arrays determine the most appropriate lectins for glycoprotein enrichment as well as for the removal of undesirable glycoproteins. Lectin microarrays could also be used for rapid and simple analysis of protein glycosylation, although they will not detect all glycans in a complex sample, nor will they provide complete structure assignment. This technology is based on binding of an intact glycoprotein or glycopeptides to the arrayed lectins, to provide a characteristic fingerprint pattern that is highly sensitive to changes in a protein's glycan composition. Hsu and Mahal (2006) have described a lectin-array protocol for high-throughput evaluation of cell-surface microbial sugars. The binding patterns of fluorescent bacteria to these arrays provided a simple means to fingerprint bacteria based on their surface carbohydrates. A beneficial aspect of lectin arrays is that the large number of lectins, each with their specific recognition pattern, provides a high level of sensitivity to changes in the glycosylation pattern. Kuno et al. (2005) and Uchiyama et al. (2006) developed a lectinmicroarray procedure based on an evanescent-field fluorescence detection principle that allowed a sensitive, real-time observation of multiple lectin-carbohydrate interactions. This method allows quantitative detection of even weak lectin-carbohydrate interactions. Fully specific signal patterns for various Cy3labeled glycoproteins, glycopeptides, and tetramethylrhodamine-labeled oligosaccharides were detected with this platform. Lee et al. (2008) have successfully used lectin arrays together with LC-ESI-MS/MS to distinguish between endothelial and fibroblast cells. In their study, nine different lectins were used to characterize cell-surface glycoproteins that would distinguish between the two different types of cells. Six potential candidate surface proteins were identified that could distinguish these cells. A similar study was also done by the same group to distinguish normal and cancerous breast cells based on differential cellular surface glycoproteins (Chen et al., 2007b). Tao et al. (2008) used lectin arrays to study cellular development and differentiation. They used lectin arrays to show mannose-dependent tropisms 


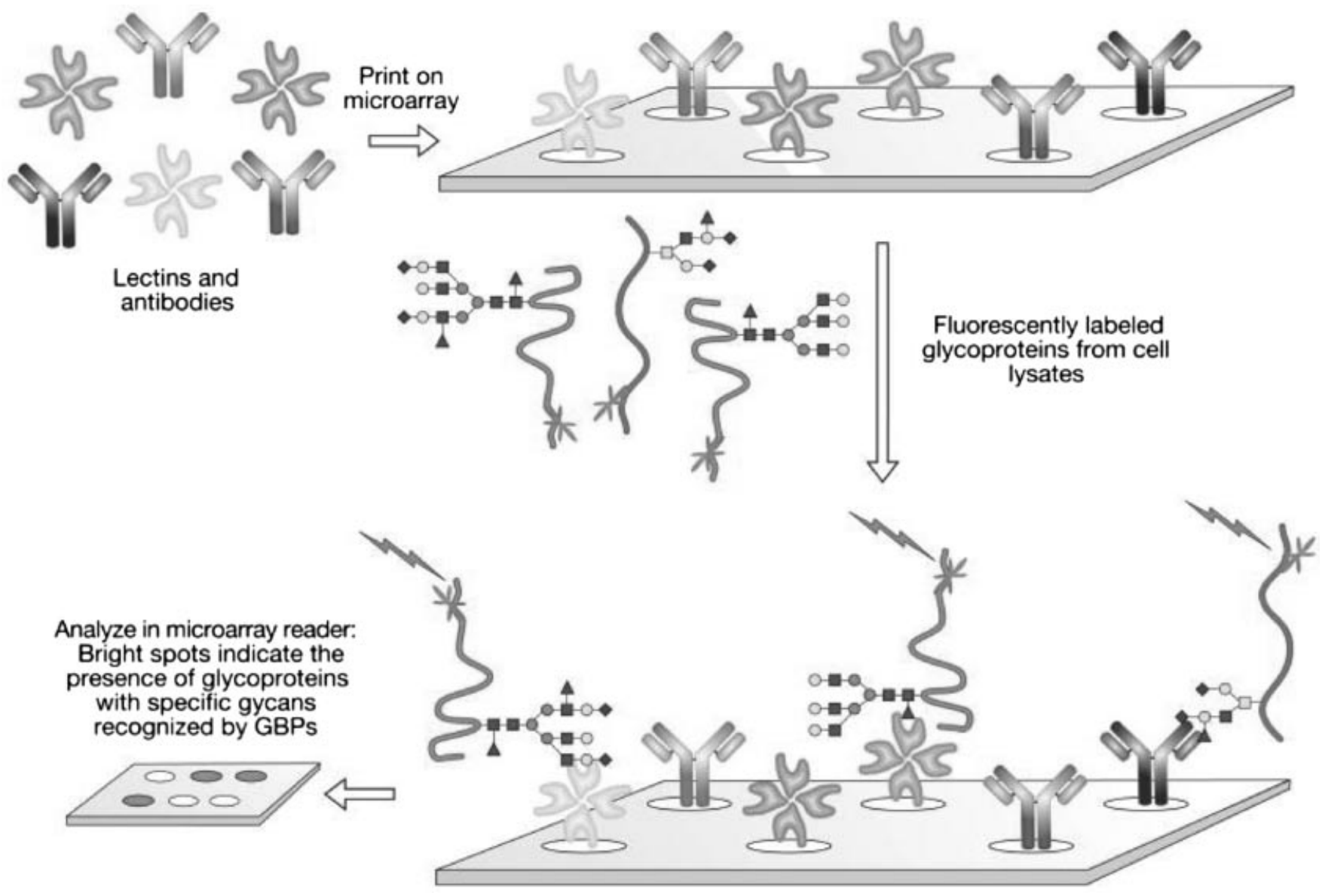

FIGURE 2. Analysis of cellular glycomes, using lectin and antibody arrays. The arrays were generated by immobilization of lectins and glycan-specific antibodies on a chip. Glycoproteins from cell or tissue samples were labeled with a fluorescent dye and incubated with the array. The fluorescent spots reflect the presence of glycoproteins that bear glycans recognized by the corresponding lectin or antibody. The technique provides minimal structural detail, but permits rapid high-throughput analysis of many samples. Intact cells or virus particles can also be interrogated on lectin microarrays. Reprinted and adapted with permission from Bertozzi and Sasisekharan (2009). Copyright 2009 by The Consortium of Glycobiology Editors, La Jolla, California.

with a model pathogen, as well as novel lectin biomarkers for cancer stem-like cells in a murine model. One problem with any microarray approach is often the small amount of probes that are found naturally. The cost of the probe is particularly notable when the probe is serum or other biological fluid that is often not available in abundant amounts. Slide processing, therefore, must be done with care to ensure that minimal amounts of the probes are used for an analysis. Nagaraj et al. (2008) have recently developed a protocol that uses piezoelectric printing to deposit sample directly onto the lectin spot on an array. This method circumvents the conventional slidehybridization process, where a slide is washed in a larger volume of probe. Instead, nanoliter amounts of probe are directly deposited onto the lectin spot with non-contact piezoelectric means. The functionality and utility of such a protocol was demonstrated by distinguishing closely related isoforms of fetuin using this technique.

Although lectin arrays and carbohydrate arrays provide valuable information about carbohydrate-interacting proteins and lectin-glycoprotein interaction, they do not allow one to screen whole glycoproteomes to study changes in an individual protein's glycan expression within that glycoproteome and changes in overall glycoprotein patterns.

\section{Glycoprotein Microarrays}

Protein microarrays are a useful screening method for whole-cell lysates, fractionated proteomes, intact glycoproteins, and antigenantibody reactions (Tao, Chen, \& Zhu, 2007; Kricka \& Master, 2008). Unlike oligonucleotides, proteins are broadly heterogeneous in size, shape, and chemistry. To maximize the quality of data obtained, choosing the surface with the best signal-to-noise ratio is critical. Glass-coated surfaces with specific chemical functionalities are very popular because they eliminate background fluorescence. Deposition of proteins on the surface, such as an epoxide-coated surface, results in covalent linkage to the glass. Nitrocellulose slides are among the most popular substrates due to their low cost. The ultrathin nitrocellulose 
layer provides a lower fluorescence background while maintaining good binding capacity. Sprenger and co-workers developed thin film-coated photoactivatable surfaces (dextran-coated glass slides) suitable for covalent immobilization of glycans, glycoconjugates, and lectins in microarray formats (Angeloni et al., 2005). In this work, standard glycoproteins were covalently immobilized, and exposed glycans were successfully profiled with lectins for fucose, sialic acid, and galactose. These platforms were also suitable for glycans and lectin immobilization which allowed for biomolecule binding to such microarray platforms and illustrated the versatility of the microarray-based tools with different applications.

One very promising strategy that has been explored is the use of multidimensional-fractionation techniques to simplify cell lysates into less-complex fractions to produce natural protein microarrays (Taylor et al., 2008). Briefly, cellular proteins from a cancer cell line are first resolved with a $\mathrm{p} I$-based fractionation with chromatofocusing or isoelectric focusing. Each fraction is separated further with reversed-phase HPLC. The fractionated proteins are lyophilized, re-suspended in a suitable buffer, and printed on a nitrocellulose-based microarray. The protein microarray is screened with sera or modification-specific detection reagent. This technique has been used by our group to study the humoral response and to identify potential serum biomarkers for prostate cancer. It is shown that specific fractions are immunoreactive against prostate cancer serum but not against serum from healthy individuals.

Based on the natural protein microarray approach, recently a method for global analysis of glycosylation patterns and detection of glycosylation alterations in cancer serum was developed (Patwa et al., 2006). This strategy uses an all-liquidphase enrichment and prefractionation methodology coupled to glycoprotein microarray technology, using a multiple lectinbased, biotin-streptavidin detection scheme. Selective detection of glycan structures was made possible by employing multiple lectins to screen glycoproteins from serum samples from normal subjects or patients with chronic pancreatitis or pancreatic cancer. The general strategy is shown in Figure 3, where a
(1)

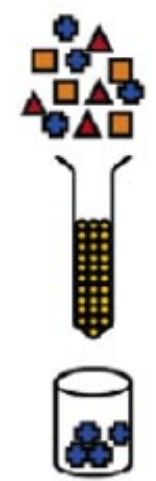

Lectin affinity purification
HFLC Separation

(2)
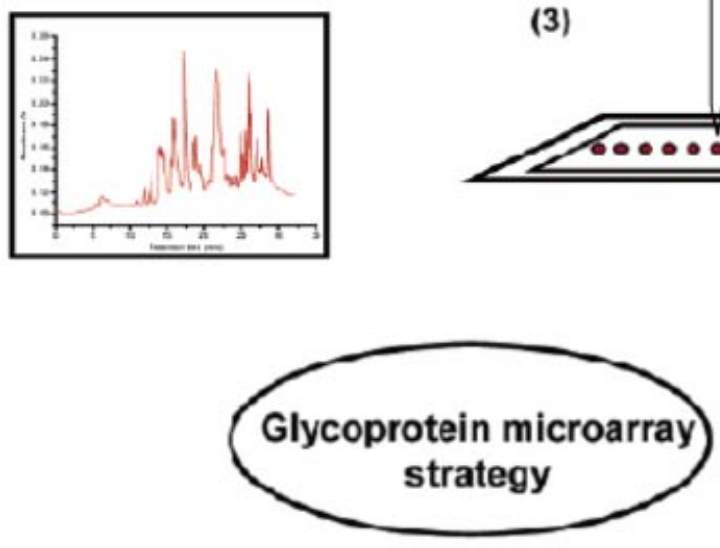

(5)

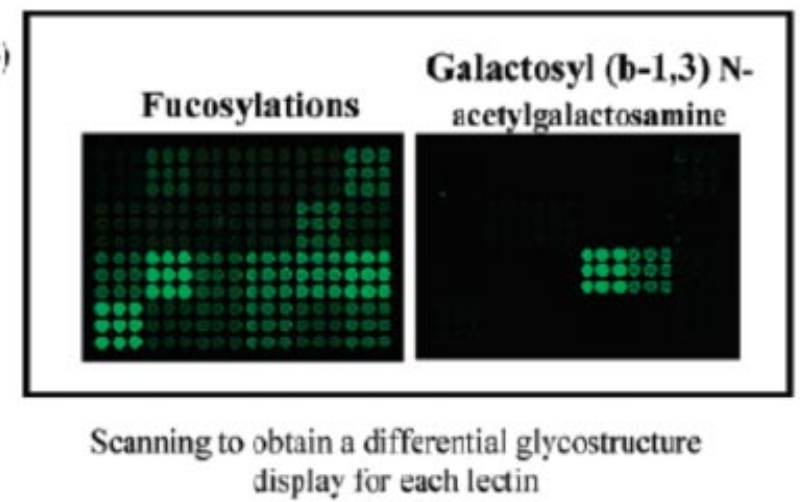

Array production by

non-contact

piezoelectric deposition

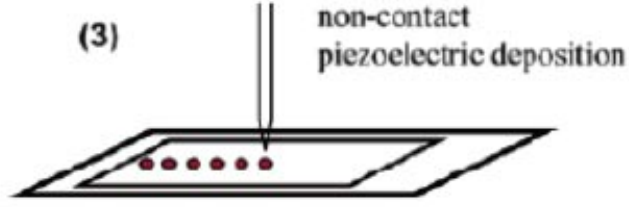

(4)

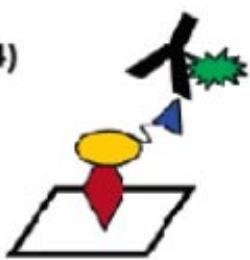

Detection (primary

detection with biotin and secondary detection with streptavidin conjugated to alexafluor

KEY:

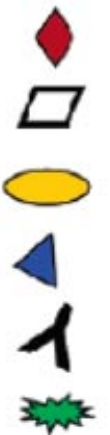

Glycoptotein

Nitrocellulose slide

Lectin

Biotin

Streptavidin

AlexaFluor555

FIGURE 3. Proposed experimental strategy to study serum glycoproteins. (1) Lectin purification with a general lectin column. (2) Non-porous reversed-phase HPLC separation and fraction collection. (3) Microarray production with a non-contact piezoelectric printing device. (4) Glycan detection with biotinylated lectin-streptavidin-Alexafluor555. (5) Image acquisition and spot analysis with Genepix 6.0 software. Reprinted with permission from Patwa et al. (2006). Copyright 2006, American Chemical Society. [Color figure can be viewed in the online issue, which is available at wileyonlinelibrary.com.] 
complex serum sample was first depleted of the top 12 most abundant proteins in human serum with an antibody column to detect low-abundance proteins. Glycoproteins were subsequently enriched from depleted fractions with a dual-lectin column that contained lectin ConA and WGA. ConA recognizes $\mathrm{N}$-linked mannose, including high-mannose-type and mannose core structures, and WGA recognizes terminal GlcNAc. Using these two lectins with broad specificities, most of the glycoproteins could be isolated. The glycoprotein pool was further fractionated with 1-D or 2-D liquid-phase separation, such as isoelectric focusing, coupled with reversed-phase HPLC. The purified glycoproteins were spotted onto nitrocellulose slides and were probed with five different biotinylated lectins followed by streptavidin conjugated to a fluorescent tag. Both maackia amurensis lectin (MAL) and sambucus nigra lectin (SNA) recognize sialic acid on the terminal branches. SNA binds preferentially to sialic acid attached to terminal galactose in an $(\alpha-2,6)$ and, to a lesser degree, an $(\alpha-2,3)$ linkage. MAL detects glycans that contain NeuAc-Gal-GlcNac with sialic acid at the 3-position of galactose. Peanut agglutinin (PNA) binds de-sialylated exposed galactosyl $(\beta-1,3)$ GalNAc, and aleuria aurantia lectin (AAL) recognizes fucose linked $(\alpha-1,6)$ to GlcNAc or $(\alpha-1,3)$ to $N$-acetyllactosamine. These five lectins covered a majority of $\mathrm{N}$-glycan types and differentiated them according to their specific structures. The printed glycoproteins were incubated with biotinylated lectins, and the bound biotinylated lectins were detected with streptavidin conjugated to AlexaFluor555. This sandwich-type detection scheme was employed because the very specific biotin-streptavidin interaction improved signal-to-noise ratios.

The specificity, reproducibility, and sensitivity of such an approach were tested with five standard glycoproteins: fetuin, asialofetuin, thyroglobulin, ribonuclease B, and transferrin. The images obtained when slides were probed with each of the lectins are shown in Figure 4. These data correlated well with previously reported glycan structures that correspond to the standard glycoproteins used in this study. The difference in the glycan structures can be readily distinguished. The use of lectins for
Con A

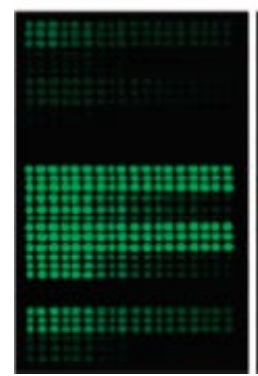

AAL

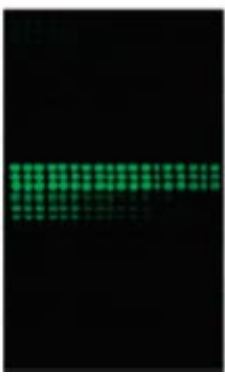

SNA

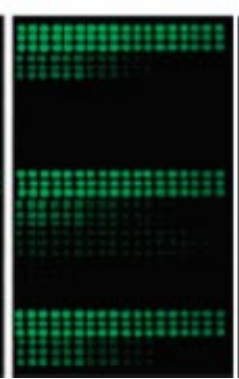

MAL

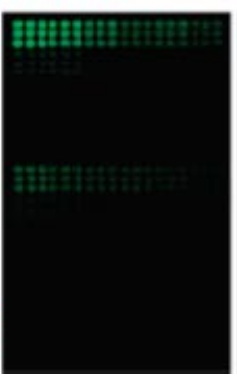

PNA

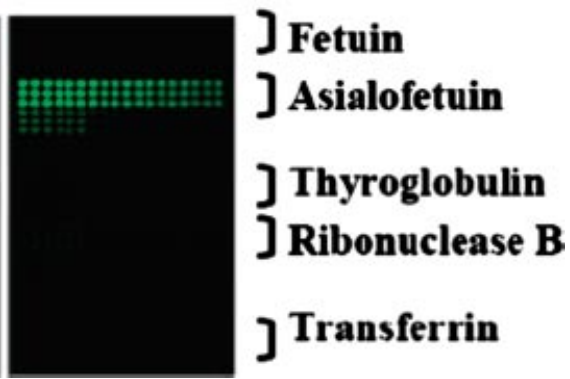

FIGURE 4. Scanned images of printed standard glycoproteins probed with different lectins. Each block bracketed on the right represents a dilution series of standards from 0.025 to $0.5 \mathrm{mg} / \mathrm{mL}$. Each dilution has been printed as nine replicates in a $3 \times 3$ block. Reprinted with permission from Patwa et al. (2006). Copyright 2006, American Chemical Society. [Color figure can be viewed in the online issue, which is available at wileyonlinelibrary.com.]

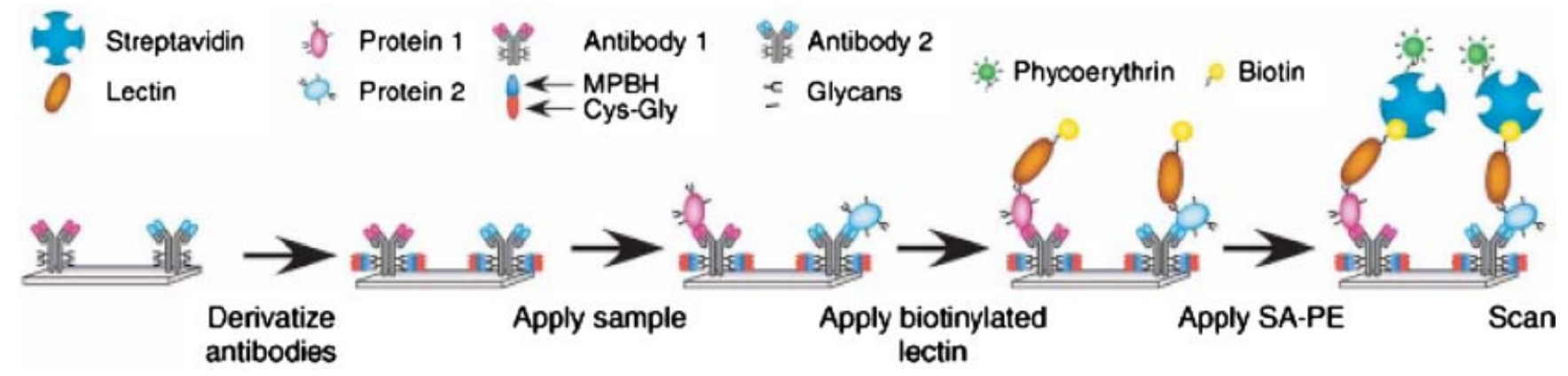

FIGURE 5. Detection of glycans on antibody arrays. The first step of this new method is the chemical derivatization of the glycans on the spotted antibodies to block lectin binding to those glycans. The cishydroxyl groups of the glycans on the spotted antibodies were gently oxidized to convert them to aldehyde groups, which react with a hydrazide-maleimide bifunctional cross-linking reagent; the resulting product reacts with a Cys-Gly dipeptide. The Cys-Gly dipeptide adds bulk to the derivatized carbohydrates to hinder lectin binding. Reprinted and adapted with permission from Chen et al. (2007). Copyright 2007, Nature Publishing Group. [Color figure can be viewed in the online issue, which is available at wileyonlinelibrary.com.] 
glycan structure detection enables the measurement of several glycoforms of each individual glycoprotein (e.g., sialylated and non-sialylated glycoforms can be distinguished with SNA). The sensitivity of this approach was approximately $5 \mathrm{fmol}$, and the variance was within $10 \%$ as determined by nine replicate spotting events for each standard protein.

Due to the complexity of some samples and limited resolution of RP-HPLC fractionation, the accuracy of the biomarker candidates identified with the glycoprotein microarray might be compromised when the differentiated fraction contains several glycoproteins and none of them is dominant. In this case the protein that contributes the most to the observed lectin binding cannot be determined. Normalization of the amount of the glycoprotein using the UV peak area can be also problematic. Follow-up experiments, such as antibody array and lectin blot, are necessary to test the validity of the finding. In terms of future developments for the glycoprotein microarray, we are looking forward to more different types of separations coupled with the a

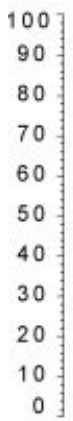

b

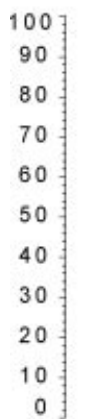

C

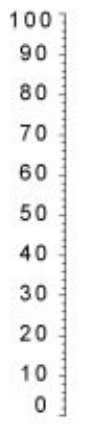

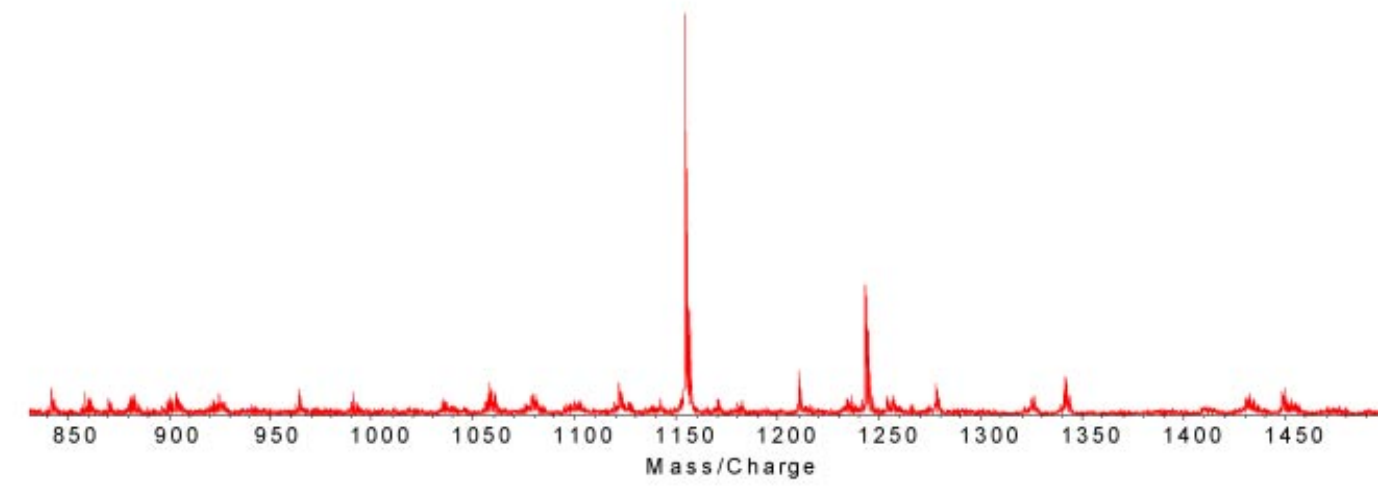
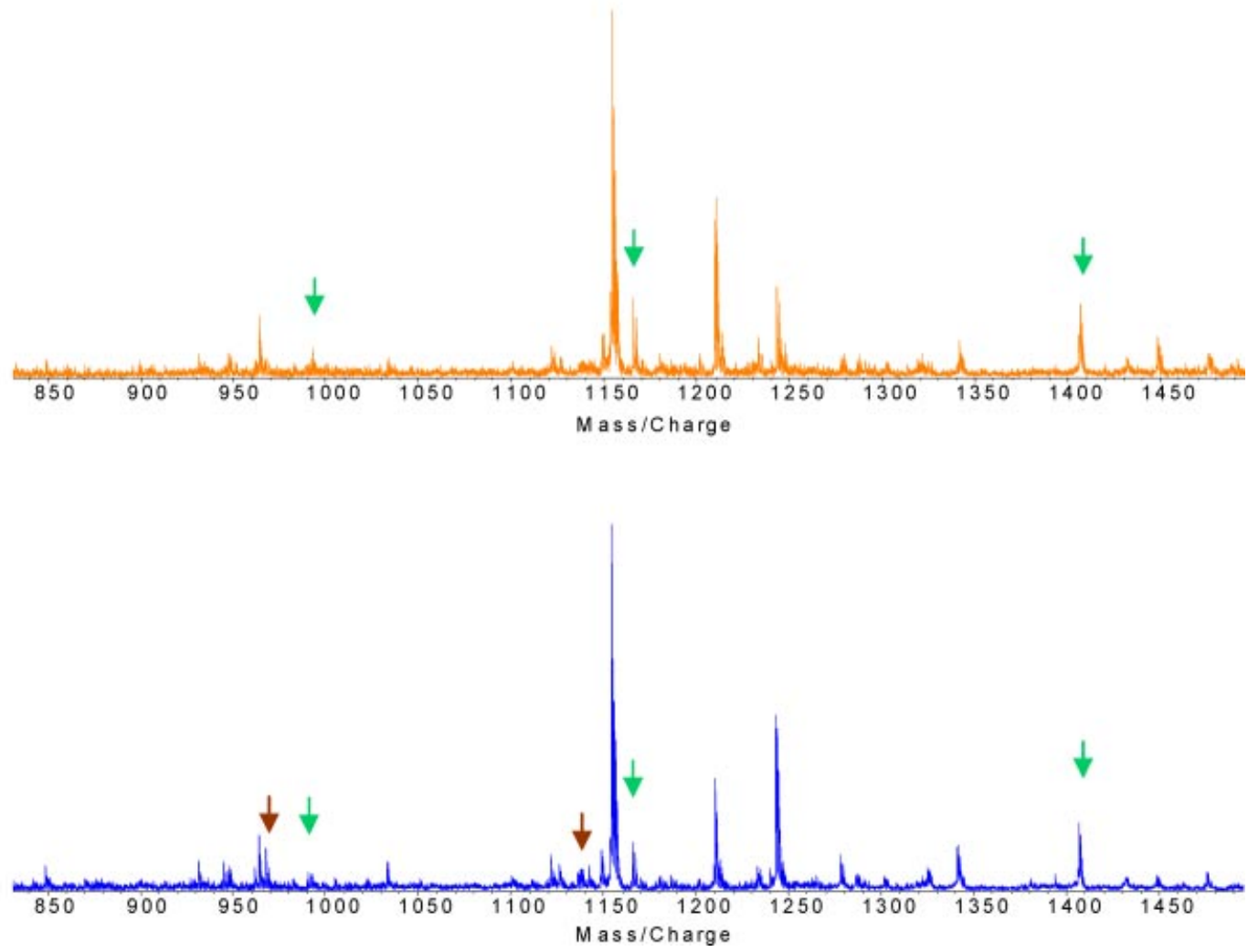

FIGURE 6. The MALDI-MS spectra generated from the microarray spots of amyloid p component antibody after on-target digestion. The peaks identified as amyloid p component were marked with green arrows, where the extra peaks that appear in (c) were marked with black arrows. a: Control spot, without incubation with serum; (b) incubated with10× diluted serum; (c) incubated with $2 \times$ diluted serum. Reprinted and adapted with permission from Li et al. (2009). Copyright 2009, American Chemical Society. [Color figure can be viewed in the online issue, which is available at wileyonlinelibrary.com.] 
microarray platform for improved fractionation especially for glycoforms.

\section{Antibody Microarrays}

The use of antibodies is a means to capture and purify specific proteins in a natural state. The antibody microarray allows the efficient, multiplexed study of multiple individual proteins from complex mixtures (Borrebaeck \& Wingren, 2007; Korf et al., 2008). The variable carbohydrate structures attached to the captured proteins can be characterized by studying the interaction between the glycans and different kinds of biotinylated lectins or glycan-binding antibodies. However, this application had been limited by the lectin-binding glycans that attach on the antibody itself. Gornik and Lauc (2007) and Chen et al. (2007a) have developed similar methods to chemically block the glycans on the antibody. Both groups treated the antibodies with sodium periodate to oxidize the cis-hydroxyl groups on the glycans into aldehyde groups, whereas Chen et al. (2007a) further sequentially modified the resulting product with a hydrazidemaleimide cross-linking reagent and a dipeptide (Fig. 5). They also demonstrated selective binding of lectins toward glycoforms generated by deriving the sample with neuraminidase which removes terminal sialic acid groups. Profiling protein and glycan variation in multiple samples with parallel-sandwich and glycan-detection assays showed cancer-associated glycan alteration on the proteins MUC1, MUC5AC, and MUC16 in pancreatic cancer cell lines stimulated by pro-inflammatory factors (Wu et al., 2008). In addition, the author suggested that inflammation might influence the cells in a specific cell-type manner because the cell lines bearing minimal or multiple markers exhibited opposite responses. Another study on serum detection of pancreatic cancer with antibody microarrays was performed to validate biomarker candidates found in previous studies (Li et al., 2009). A 67\% increased response to lectin SNA was found on alpha-1-beta glycoprotein in the serum of pancreatic cancer patients compared to the serum of patients with chronic pancreatitis and normal controls. The results were provided by statistical analysis of the data collected from 183 samples to ensure reproducibility. In addition to the fabrication of an antibody array on glass slides, there is an alternate format, which is crafted by depositing antibodies into individual wells on a multiple-well plate. Meany et al. (2009) investigated the glycosylation of PSA and found that the alteration of the glycan structure of the PSA was more relevant to the progression of prostate cancer. An antibody-assisted lectin-profiling (ALP) platform has also been evaluated by Kuno et al. (2009). In this approach, a glycoprotein of interest was first enriched from a medium with an antibody. The glycoprotein was quantified with

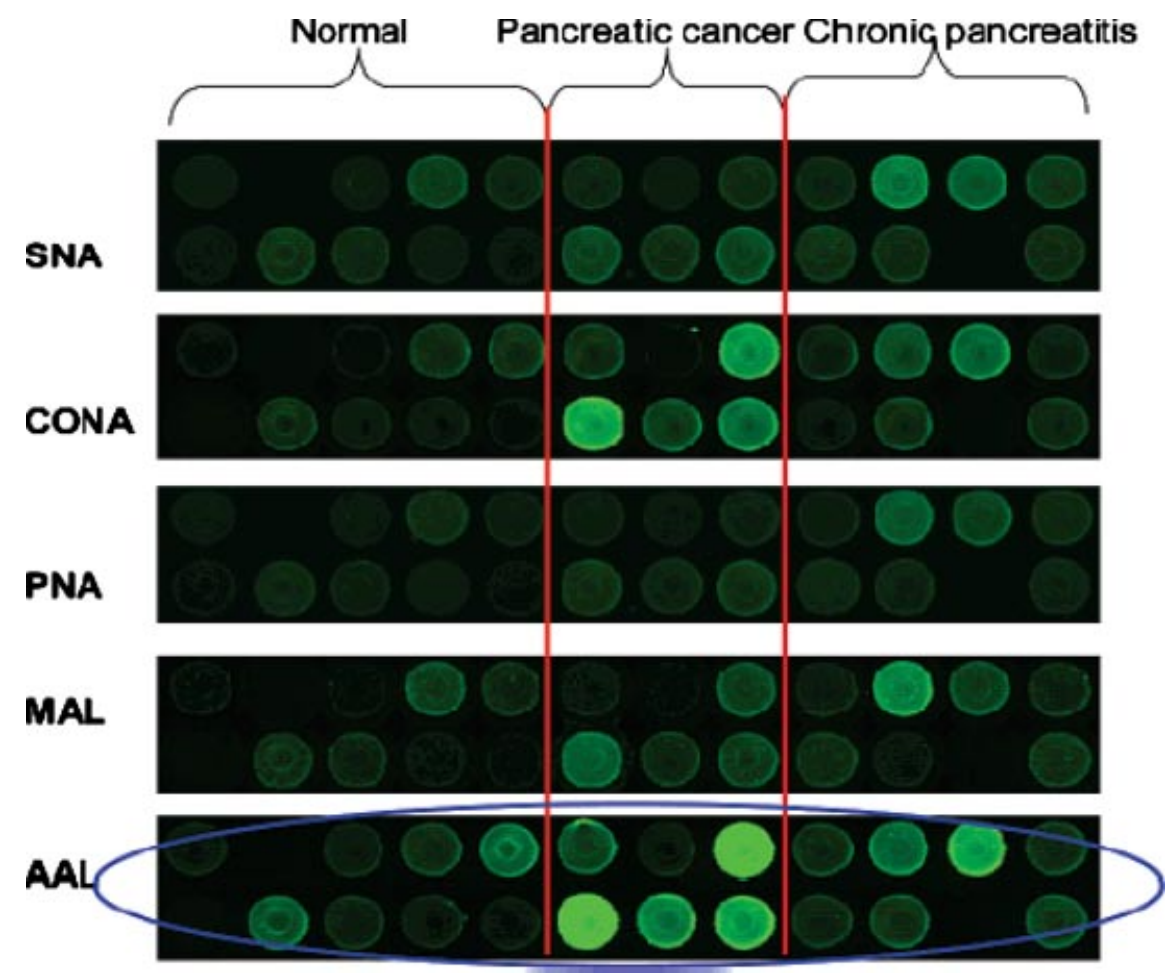

FIGURE 7. Sections of glycoprotein microarray to compare one fraction from NPS-RP-HPLC across all 24 samples. Each panel is a section of identical arrays probed with lectin indicated on the left side of the panel. It was observed that this fraction contained proteins that were predominantly mannosylated and fucosylated. It was also observed that the level of glycosylation (based on raw microarray data) was higher in cancer samples compared to the controls. Reprinted with permission from Zhao et al. (2007b). Copyright 2007 American Chemical Society. [Color figure can be viewed in the online issue, which is available at wileyonlinelibrary.com.] 
blotting experiments, and lectin profiling of the protein was performed. This approach revealed disease- and tissue-specific glycosylation changes in model systems of PSA and podoplanin at picomole levels.

In addition to detection with lectin- and glycan-binding antibody strategies, mass spectrometry can potentially play an important role to read microarrays. Evans-Nguyen et al. (2008) prepared antibody microarrays, which capture peptides from a simple mixture on gold- and polymer-modified glass slides and performed MALDI-MS by accurately depositing matrix onto antibody spots with a microarray printer. Other work includes an on-slide digestion technique, which has been developed to analyze the glycoproteins captured by the antibody array with MALDI-MS (Li et al., 2009). After the slides are hybridized with serum, an appropriate volume of trypsin solution was printed onto the antibody spots, and the slides were kept in a humidified chamber for $3 \mathrm{~min}$ before the matrix was applied to the spots. Although the enzyme digested the captured glycoproteins and the antibody, the antibody peaks could be excluded by adding a blank block on the slides (see Fig. 6). This on-slide digestion technique identified several target glycoproteins for the antibodies from serum by MALDI-MS/MS. The identities of the glycoproteins proved the specificity of the antibodies when they were incubated with properly diluted serum.

Antibody-lectin sandwich microarray provides a means to measure glycosylation change on specific proteins captured from complex samples with lectin probes in a high-throughput array format. Compared to HPLC-MS, it is not only a simple and reproducible way of investigating a large number of samples but also a type of assay that analyzes proteins in their native form which can be crucial for understanding the functional role of glycoproteins in the biological environment. Although the antibody-lectin sandwich microarray platform is able to distinguish glycoforms with different glycan structures, the use of fluorescence provides less detailed structural information than MS/MS. The introduction of mass spectrometry-based label-free detection would provide a means for further characterization of the glycan structure. It should be noted that insufficient blocking

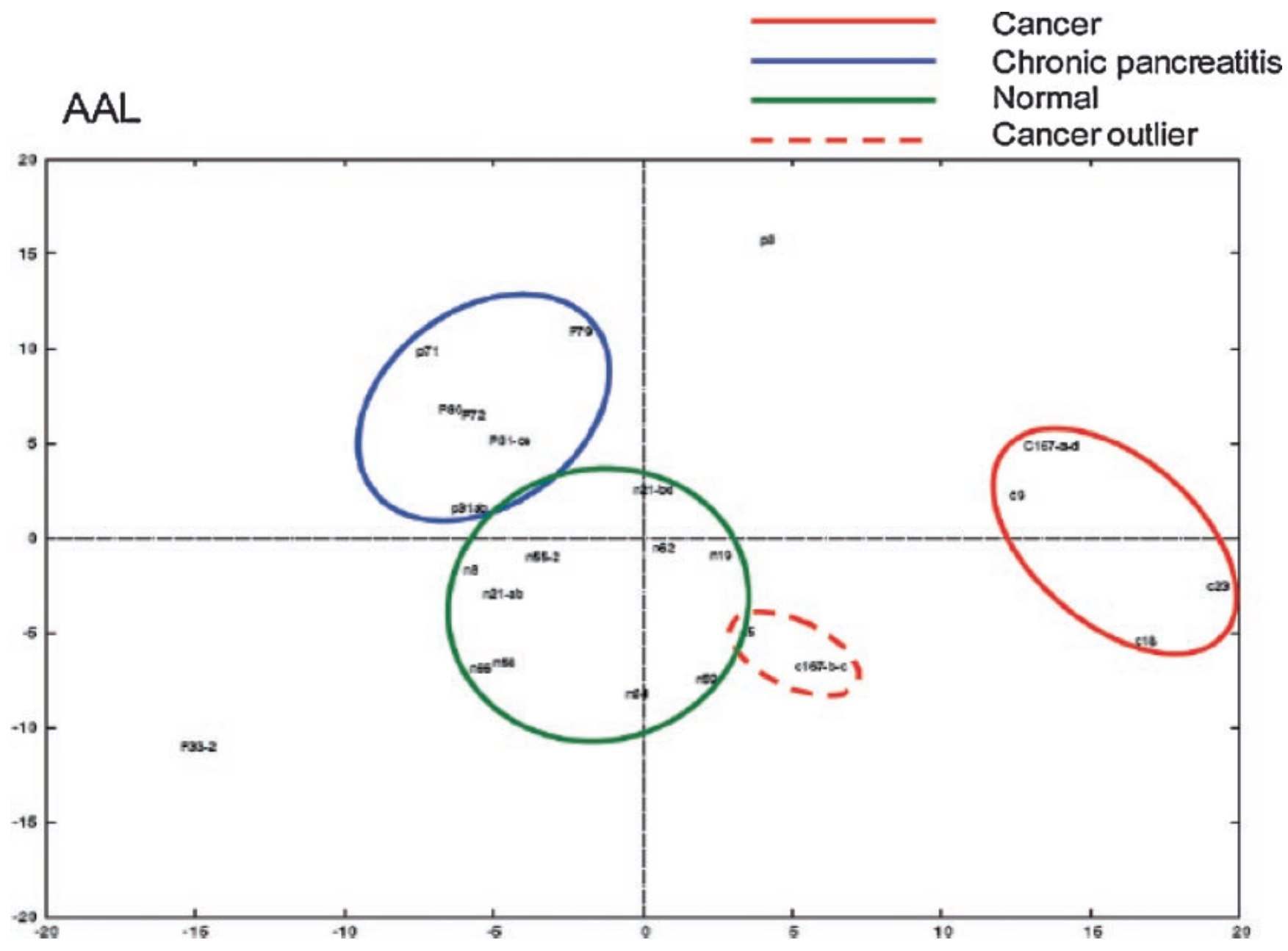

FIGURE 8. The normalized glycoprotein microarray responses to lectin AAL were visualized with principal component analysis (PCA). Twenty-four serum samples (10 normal, 8 chronic pancreatitis, and 6 pancreatic cancers) were studied. The figure shows the clustering of serum samples obtained from patients with pancreatic cancer, chronic pancreatitis, or normal subjects. Reprinted with permission from Zhao et al. (2007b). Copyright 2007, American Chemical Society. 


\section{Complement C3}

A
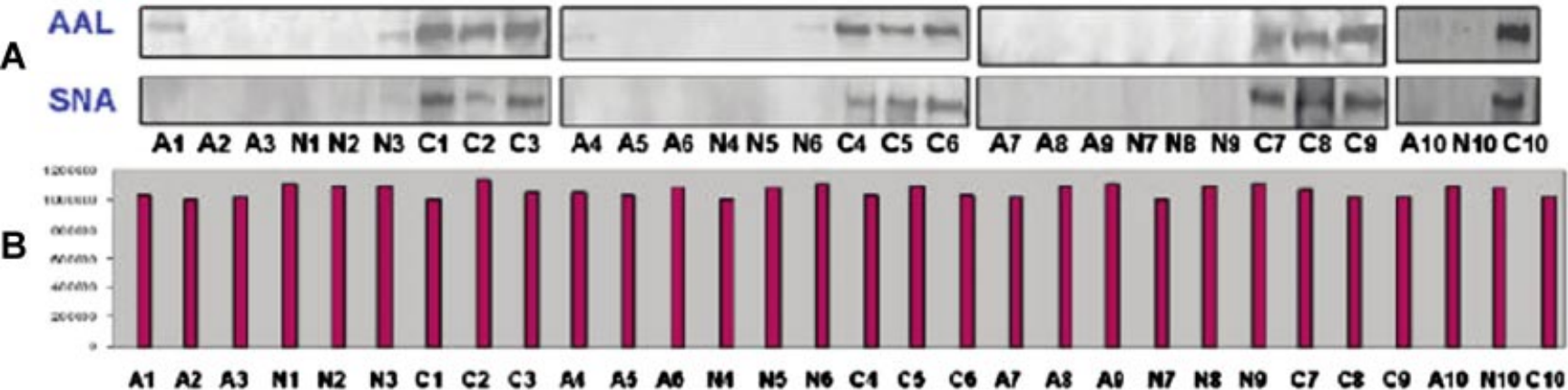

\section{Histidine-rich glycoprotein}

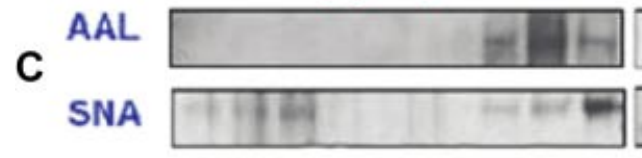

A1 A2 A3 n1 n2 N3 C1 C2 C3 a4 As ag n4 ns ng Cl C5 C
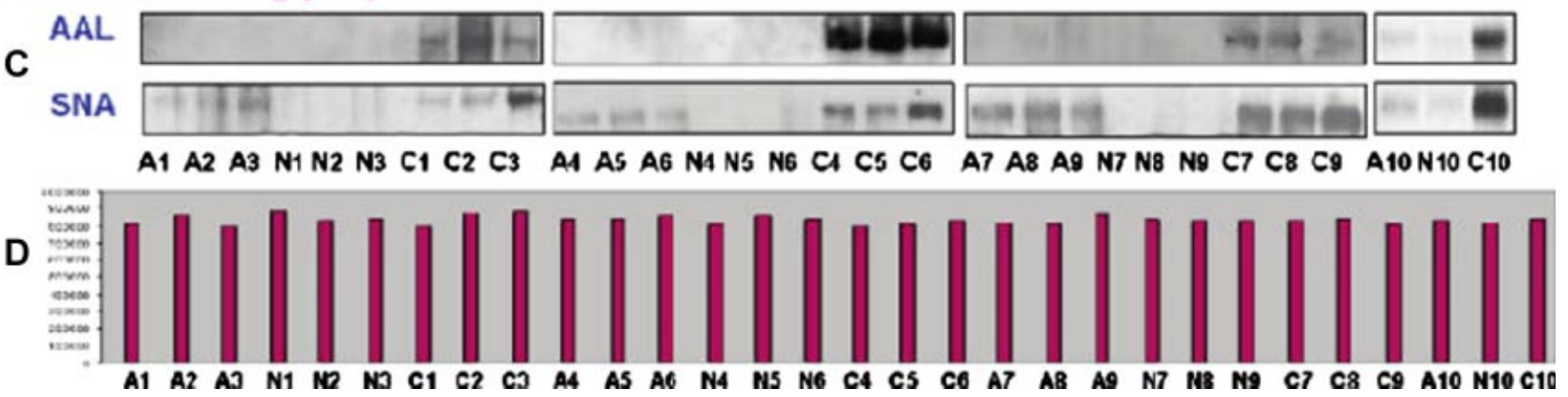

FIGURE 9. Elevated fucosylation and sialylation of complement C3 (A) and histidine-rich glycoprotein (C) investigated with AAL and SNA blot analysis. The corresponding protein expression levels are shown in (B) for complement C3 and (D) for histidine-rich glycoprotein, respectively. Reprinted with permission from from Qiu et al. (2008). Copyright 2008, American Chemical Society. [Color figure can be viewed in the online issue, which is available at wileyonlinelibrary.com.]

efficiency with some of the lectins such as ConA limits the detection of several interesting glycan structures. To reduce the noise or background, we are searching for other chemical blocking strategies and even other platforms for the next generation of antibody-lectin assays.

\section{E. Glycoprotein Microarray Applications}

The glycoprotein microarray method has been applied to the glycosylation profiling of pancreatic cancer, colon cancer, and esophageal cancer sera (Zhao et al., 2007b; Qiu et al., 2008).

A scanned image of one HPLC fraction from 10 normal, 8 pancreatitis, and 6 pancreatic cancer serum samples detected by the five lectins is shown in Figure 7. The normalized glycoprotein microarray responses to lectins were visualized by principal component analysis (PCA). The response to lectin AAL, which binds to fucosylation sites, generally distinguished the three clinical groups (Fig. 8). Pancreatic cancer samples clustered farther away from normal compared to chronic pancreatitis, especially in response to fucosylation and sialylation. Altered glycosylation patterns have also been observed in individual proteins, such as hemopexin, antithrombin-III, and kininogen-1 in pancreatic cancer sera. One of the advantages of this approach is that the differential response can be tracked back to the original fraction from which the spot was created. A combination of chromatographic separation, mass spectrometry, and other characterization techniques can be used to analyze and define the target glycome. In this approach, the altered glycosylation was determined with a combination of Western blotting and mass spectrometry. The results from peptide mapping and Western blotting experiments confirmed the observations made in the glycoprotein microarray experiments. For example, elevated sialylation on one glycosylation site was detected on haptoglobin-related protein with peptide mass mapping, and increased fucosylation was also detected with the lectin-blotting experiment. These results were consistent with the array study, where over-expressed fucosylation and sialylation were both observed in pancreatic cancer serum.

A study similar to the one described above determined specific glycosylation changes that might occur as a function of the development of colorectal cancer and esophageal cancers (Qiu et al., 2008). Glycoproteins were isolated from sera of healthy individuals and patients with colonic adenomas or colorectal and esophageal cancers. Separation by LC followed by microarray generation and hybridization together with statistical treatment of all data elucidated some key proteins that might be involved in cancer development. An additional piece of research that was done in these studies involved confirmation of the glycosylation sites in the glycoprotein of interest and an unblinded validation with independent samples from each class 
of human sera studied. Glycoproteins that were unique to a specific class of sera were isolated from all validation sera with HPLC, and a lectin blot validated the glycosylation levels of those proteins. Results confirmed those results obtained with the glycoprotein microarray approach (Fig. 9). A similar approach is currently used to analyze glycosylation changes present during the development of diabetes.

Protein glycosylation screening analysis might allow for the detection of alterations in protein glycosylation in samples from patients with different clinical conditions. Not only alterations in absolute protein levels, but importantly, changes in PTM on the protein, such as glycosylation, could indicate the presence, absence, or severity of a disease. The ability to rapidly and sensitively screen protein glycosylation patterns and detect glycosylation alterations might provide a potentially efficient means to screen patients for cancer, such as pancreatic cancer and possibly other cancers.

\section{CONCLUSION}

There is a dramatic increase in the number of publications that use microarray technology. Increased advances are also being made in other technologies that could potentially be used together with microarray technologies, especially the integration of mass spectrometry as a label-free detection method in glycan and antibody array techniques. Protein glycosylation analysis with protein microarrays has proven to be a high throughput and successful technique that not only provides a high level of information about glycoprotein abundance changes but also sheds light on more specific glycan-associated changes responsible for disease progression or disease presence. Combining this technology with advancing complementary techniques such as affinity enrichment, sample depletion to eliminate highabundance proteins, and mass spectrometry has great potential to further utilize microarray technology to aid in diagnosis or management of human disease.

\section{ACKNOWLEDGMENTS}

We generously acknowledge the support of this work under grants from the National Institutes of Health NIH R01GM4900 and the National Cancer Institute under grants 1R21CA124441 and R01 CA106402 and the NCI/EDRN under a subcontract from Johns Hopkins University.

\section{REFERENCES}

Adams EW, Ratner DM, Bokesch HR, McMahon JB, O'Keefe BR, Seeberger PH. 2004. Oligosaccharide and glycoprotein microarrays as tools in HIV glycobiology: Glycan-dependent gp120/protein interactions. Chem Biol 6:875-881.

Amon S, Zamfir AD, Rizzi A. 2008. Glycosylation analysis of glycoproteins and proteoglycans using capillary electrophoresis-mass spectrometry strategies. Electrophoresis 29:2485-2507.
Angeloni S, Ridet JL, Kusy N, Gao H, Crevoisier F, Guinchard S, Kochhar S, Sigrist H, Sprenger N. 2005. Glycoprofiling with micro-arrays of glycoconjugates and lectins. Glycobiology 15:31-41.

Arnold JN, Saldova R, Hamid UMA, Rudd PM. 2008. Evaluation of the serum $\mathrm{N}$-linked glycome for the diagnosis of cancer and chronic inflammation. Proteomics 8:3284-3293.

Bertozzi CR, Sasisekharan R. 2009. Glycomics. In: Varki A, editor. Essentials of glycobiology. 2nd edition, Chapter 48. California: The Consortium of Glycobiology Editors.

Borrebaeck CA, Wingren C. 2007. High-throughput proteomics using antibody microarrays: An update. Expert Rev Mol Diagn 7:673-686.

Castle JD. 2004. Overview of cell fractionation. Chapter 4, Unit 4. 1. Current Protocols in Protein Science, Hoboken, NY: Wiley.

Chen SM, LaRoche T, Hamelinck D, Bergsma D, Brenner D, Simeone D, Brand RE, Haab BB. 2007a. Multiplexed analysis of glycan variation on native proteins captured by antibody microarrays. Nat Methods 4:437444.

Chen SY, Zheng T, Shortreed MR, Alexander C, Smith LM. 2007b. Analysis of cell surface carbohydrate expression patterns in normal and tumorigenic human breast cell lines using lectin arrays. Anal Chem 79:5698-5702.

Codington JF, Haavik S. 1992. Epiglycanin-A carcinoma-specific mucintype glycoprotein of the mouse TA3 tumor. Glycobiology 2:173-180.

Cyster JG, Shotton DM, Williams AF. 1991. The dimensions of the lymphocyte-t glycoprotein leukosialin and identification of linear protein epitopes that can be modified by glycosylation. EMBO J 10:893-902.

Dalpathado DS, Desaire H. 2008. Glycopeptide analysis by mass spectrometry. Analyst 133:731-738.

Dayarathna MK, Hancock WS, Hincapie M. 2008. A two step fractionation approach for plasma proteomics using immunodepletion of abundant proteins and multi-lectin affinity chromatography: Application to the analysis of obesity, diabetes, and hypertension diseases. J Sep Sci 31:1156-1166.

de Boer AR, Hokke CH, Deelder AM, Wuhrer M. 2007. General microarray technique for immobilization and screening of natural glycans. Anal Chem 21:8107-8113

Dennis JW, Laferte S, Waghorne C, Breitman ML, Kerbel RS. 1987. Beta-1-6 branching of Asn-linked oligosaccharides is directly associated with metastasis. Science 236:582-585.

Dotan N, Altstock RT, Schwarz M, Dukler A. 2006. Anti-glycan antibodies as biomarkers for diagnosis and prognosis. Lupus 15:442-450.

Evans-Nguyen KM, Tao SC, Zhu H, Cotter RJ. 2008. Protein arrays on patterned porous gold substrates interrogated with mass spectrometry: Detection of peptides in plasma. Anal Chem 80:1448-1458.

Fang XM, Zhang WW. 2008. Affinity separation and enrichment methods in proteomic analysis. J Proteome Res 71:284-303.

Feizi T, Childs RA. 1994. Neoglycolipids-Probes in structure-function assignments to oligosaccharides. Methods Enzymol 242:205-217.

Feizi T, Stoll MS, Yuen CT, Chai WG, Lawson AM. 1994. NeoglycolipidsProbes of oligosaccharide structure, antigenity, and function. Methods Enzymol 230:484-519.

Ferretti G, Felici A, Papaldo P, Fabi A, Cognetti F. 2007. HER2/neu role in breast cancer: From a prognostic foe to a predictive friend. Curr Opin Obstet Gynecol 19:56-62.

Gauthier DJ, Lazure C. 2008. Complementary methods to assist subcellular fractionation in organellar proteomics. Expert Rev Proteomics 5:603617.

Geisow MJ. 1992. Glycoprotein glycans-Roles and controls. Trends Biotechnol 10:333-335.

Gornik O, Lauc G. 2007. Enzyme linked lectin assay (ELLA) for direct analysis of transferrin sialylation in serum samples. Clin Biochem 40:718-723. 
Helenius A, Aebi M. 2001. Intracellular functions of N-linked glycans. Science 291:2364-2369.

Hirabayashi J. 2008a. Concept, strategy and realization of lectin-based glycan profiling. J Biochem 144:139-147.

Hirabayashi J. 2008b. Lectin-based structural glycomics: Glycoproteomics and glycan profiling. Glycoconj J 21:35-40.

Hirabayashi J, Kasai K. 2002. Separation technologies for glycomics. J Chromatogr B 771:67-87.

Hogdall E. 2008. Cancer antigen 125 and prognosis. Curr Opin Obstet Gynecol 20:4-8.

Horlacher T, Seeberger PH. 2008. Carbohydrate arrays as tools for research and diagnostics. Chem Soc Rev 7:1414-1422.

Hsu KL, Mahal LK. 2006. A lectin microarray approach for the rapid analysis of bacterial glycans. Nat Protoc 1:543-549.

Korf U, Henjes F, Schmidt C, Tresch A, Mannsperger H, Lobke C, Beissbarth T, Poustka A. 2008. Antibody microarrays as an experimental platform for the analysis of signal transduction networks. Adv Biochem Eng Biotechnol 110:153-175.

Kościelak J. 1995. Diseases of aberrant glycosylation. Acta Biochim Pol 42:1-10.

Kricka LJ, Master SR. 2008. Validation and quality control of protein microarray-based analytical methods. Mol Biotechnol 38:19-31.

Kullolli M, Hancock WS, Hincapie M. 2008. Preparation of a highperformance multi-lectin affinity chromatography (HP-M-LAC) adsorbent for the analysis of human plasma glycoproteins. J Sep Sci 31:2733-2739.

Kuno A, Uchiyama N, Koseki-Kuno S, Ebe Y, Takashima S, Yamada M, Hirabayashi J. 2005. Evanescent-field fluorescence-assisted lectin microarray: A new strategy for glycan profiling. Nat Methods 11:851-856.

Kuno A, Kato Y, Matsuda A, Kaneko MK, Ito H, Amano K, Chiba Y, Narimatsu H, Hirabayashi J. 2009. Focused differential glycan analysis with the platform antibody-assisted lectin profiling for glycan-related biomarker verification. Mol Cell Proteomics 8:99-108.

Laurent N, Voglmeir J, Flitsch SL. 2008. Glycoarrays-Tools for determining protein-carbohydrate interactions and glycoenzyme specificity. Chem Commun 37:4400-4412.

Lebrilla CB, An HJ. 2009. The prospects of glycan biomarkers for the diagnosis of diseases. Mol Biosyst 5:17-20.

Lee JE, Mirza SP, Didier DN, Scalf M, Olivier M, Greene AS, Smith LM. 2008. Identification of cell surface markers to differentiate rat endothelial and fibroblast cells using lectin arrays and LC-ESI-MS/ MS. Anal Chem 21:8269-8275.

Levitt JM, Slawin KM. 2007. Prostate-specific antigen and prostate-specific antigen derivatives as predictors of benign prostatic hyperplasia progression. Curr Urol Rep 8:269-274.

Li C, Simeone DM, Brenner DE, Anderson MA, Shedden KA, Ruffin MT, Lubman DM. 2009. Pancreatic cancer serum detection using a lectin/ glyco-antibody array method. J Proteome Res 8:483-492.

Liu Y, Feizi T, Carnpanero-Rhodes MA, Childs RA, Zhang YN, Muiioy B, Evans PG, Osborn HMI, Otto D, Crocker PR, Chai WC. 2007. Neoglycolipid probes prepared via oxime ligation for microarray analysis of oligosaccharide-protein interactions. Chem Biol 14:847859.

Lotan R. 1979. Purification of cell-membrane glycoproteins by lectin affinitychromatography. Biochim Biophys Acta 559:329-376.

Meany DL, Zhang Z, Sokoll LJ, Zhang H, Chan DW. 2009. Glycoproteomics for prostate cancer detection: Changes in serum PSA glycosylation patterns. J Proteome Res 8:613-619.

Mechref Y, Madera M, Novotny MV. 2008. Glycoprotein enrichment through lectin affinity techniques. Methods Mol Biol 424:373-396.

Nagaraj VJ, Eaton S, Thirstrup D, Wiktor P. 2008. Piezoelectric printing and probing of lectin NanoProbeArrays for glycosylation analysis. Biochem Biophys Res Commun 375:526-530.
Nelson BP, Grimsrud TE, Liles MR, Goodman RM, Corn RM. 2001. Surface plasmon resonance imaging measurements of DNA and RNA hybridization adsorption onto DNA microarrays. Anal Chem 73:1-7.

Ohyama C. 2008. Glycosylation in bladder cancer. Int J Clin Oncol 13:308313.

Park S, Lee MR, Shin I. 2008. Carbohydrate microarrays as powerful tools in studies of carbohydrate-mediated biological processes. Chem Commun 37:4389-4399.

Patwa TH, Zhao J, Anderson MA, Simeone DM, Lubman DM. 2006. Screening of glycosylation patterns in serum using natural glycoprotein microarrays and multi-lectin fluorescence detection. Anal Chem 78:6411-6421.

Plavina T, Wakshull E, Hancock WS, Hincapie M. 2007. Combination of abundant protein depletion and multi-lectin affinity chromatography (M-LAC) for plasma protein biomarker discovery. J Proteome Res 6:662-671.

Qiu YH, Patwa TH, Xu L, Shedden K, Misek DE, Tuck M, Jin G, Ruffin MT, Turgeon DK, Synal S, Bresalier R, Marcon N, Brenner DE, Lubman DM. 2008. Plasma glycoprotein profiling for colorectal cancer biomarker identification by lectin glycoarray and lectin blot. J Proteome Res 7:1693-1703.

Rajeswari P, Natarajan R, Nadler JL, Kumar D, Kalra K. 1991. Glucose induces lipid-peroxidation and inactivation of membrane-associated ion-transport enzymes in human erythrocytes in vivo and in vitro. J Cell Physiol 149:100-109.

Ratner DM, Seeberger PH. 2007. Carbohydrate microarrays as tools in HIV glycobiology. Curr Pharm Des 13:173-183.

Robbe C, Michalski JC, Capon C. 2006. Structural determination of o-glycans by tandem mass spectrometry. In: Brockhausen I, editor. Methods in molecular biology. New Jersey: Humana Press, Inc. pp. 109-123.

Stevens J, Blixt O, Paulson JC, Wilson IA. 2006. Glycan microarray technologies: Tools to survey host specificity of influenza viruses. Nat Rev Microbiol 11:857-864.

Su J, Mrksich M. 2002. Using mass spectrometry to characterize selfassembled monolayers presenting peptides, proteins, and carbohydrates. Angew Chem Int Ed 41: 4715-4718.

Tao SC, Chen CS, Zhu H. 2007. Applications of protein microarray technology. Comb Chem High Throughput Screen 10:706-718.

Tao SC, Li Y, Zhou JB, Qian J, Schnaar RL, Zhang Y, Goldstein IJ, Zhu H, Schneck JP. 2008. Lectin microarrays identify cell-specific and functionally significant cell surface glycan markers. Glycobiology 18:761-769.

Taylor BS, Pal M, Yu JJ, Laxman B, Kalyana-Sundararri S, Zhao R, Menon A, Wei JT, Nesvizhskii AI, Ghosh D, Omenn GS, Lubman DM, Chinnaiyan AM, Sreekumar A. 2008. Humoral response profiling reveals pathways to prostate cancer progression. Mol Cell Proteomics 7:600-611.

Uchiyama N, Kuno A, Koseki-Kuno S, Ebe Y, Horio K, Yamada M, Hirabayashi J. 2006. Development of a lectin microarray based on an evanescent-field fluorescence principle. Methods Enzymol 415:341351.

Uttamchandani M, Yao SQ. 2008. Peptide microarrays: Next generation biochips for detection, diagnostics and high-throughput screening. Curr Pharm Des 14:2428-2438.

Voduc D, Kenney C, Nielsen TO. 2008. Tissue microarrays in clinical oncology. Semin Radiat Oncol 18:89-97.

Wada Y, Azadi P, Costello CE, Dell A, Dwek RA, Geyer H, Geyer R, Kakehi K, Karlsson NG, Kato K, Kawasaki N, Khoo KH, Kim S, Kondo A, Lattova E, Mechref Y, Miyoshi E, Nakamura K, Narimatsu H, Novotny MV, Packer NH, Perreault H, Peter-Katalinic J, Pohlentz G, Reinhold VN, Rudd PM, Suzuki A, Taniguchi N. 2007. Comparison of the methods for profiling glycoprotein glycans-HUPO Human Disease Glycomics/Proteome Initiative multi-institutional study. Glycobiology 17:411-422. 
Wang DN, Carroll GT, Turro NJ, Koberstein JT, Kovac P, Saksena R, Adamo R, Herzenberg LA, Herzenberg LA, Steinman L. 2007. Photogenerated glycan arrays identify immunogenic sugar moieties of Bacillus anthracis exosporium. Proteomics 7:180184.

Werz DB, Ranzinger R, Herget S, Adibekian A, von der Lieth CW, Seeberger PH. 2007. Exploring the structural diversity of mammalian carbohydrates ("Glycospace") by statistical databank analysis. ACS Chem Biol 2:685-691.

Wu YM, Nowack DD, Omenn GS, Haab BB. 2008. Mucin glycosylation is altered by pro-inflammatory signaling in pancreatic-cancer cells. Pancreas 37:502.

Wuhrer M, Catalina MI, Deelder AM, Hokke CH. 2007. Glycoproteomics based on tandem mass spectrometry of glycopeptides. J Chromatogr B 849:115-128.

Wuhrer M, de Boer AR, Deelder AM. 2009. Structural glycomics using hydrophilic interaction chromatography (HILIC) with mass spectrometry. Mass Spectrom Rev 28:192-206.
Yang ZP, Hancock WS. 2005. Monitoring glycosylation pattern changes of glycoproteins using multi-lectin affinity chromatography. J Chromatogr A 1070:57-64.

Zhang Y, Go EP, Desaire H. 2008. Maximizing coverage of glycosylation heterogeneity in MALDI-MS analysis of glycoproteins with up to 27 glycosylation sites. Anal Chem 80:3144-3158.

Zhao J, Patwa TH, Qiu WL, Shedden K, Hinderer R, Misek DE, Anderson MA, Simeone DM, Lubman DM. 2007a. Glycoprotein microarrays with multi-lectin detection: Unique lectin binding patterns as a tool for classifying normal, chronic pancreatitis and pancreatic cancer sera. J Proteome Res 6:1864-1874.

Zhao J, Qiu WL, Simeone DM, Lubman DM. 2007b. N-linked glycosylation profiling of pancreatic cancer serum using capillary liquid phase separation coupled with mass spectrometric analysis. J Proteome Res 6:1126-1138

Zhao J, Patwa TH, Lubman DM, Simeone DM. 2008. Protein biomarkers in cancer: Natural glycoprotein microarray approaches. Curr Opin Mol Ther 10:602-610.

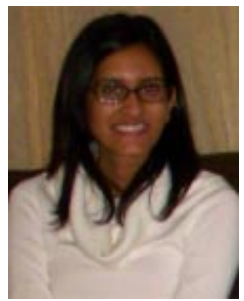

Tasneem H. Patwa received her bachelor's degree in Chemistry at Wellesley College, Wellesley, Massachussetts in 2003 with the distinction Magna Cum Laude. She carried out her PhD program at the University of Michigan, Ann Arbor, under professor David M. Lubman's mentoring. Her research primarily focused on highlighting phosphoprotein and glycoprotein differences as a function of disease progression by integrating 2-D liquid separations, protein microarrays, and mass spectrometry. She is currently a senior scientist within Pfizer Global Research and Development in Groton, CT.

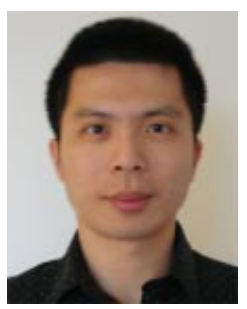

Chen Li received his BS in Chemistry from Fudan University in Shanghai, China, in 2004. $\mathrm{He}$ is a $\mathrm{PhD}$ candidate in the Department of Chemistry, University of Michigan, Ann Arbor. His research interest is application of HPLC, mass spectrometry, and microarray-based multiplexing assay in glycoprotein study.

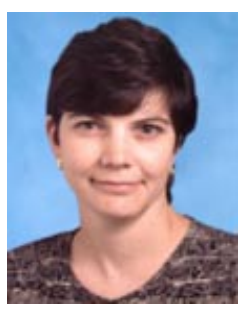

Diane M. Simeone, MD, is the Lazar Greenfield Professor of Surgery at the University of Michigan. Dr. Simeone received her bachelor's degree from Brown University in Providence, Rhode Island, and a medical degree from Duke University Medical School in Durham, North Carolina. She completed her General Surgery residency training in 1995 at the University of Michigan Medical Center at which time she joined the faculty. She is the Director of the Multidisciplinary Pancreatic Tumor Program and the Co-Director of the Gastrointestinal Oncology Program at the University of Michigan Comprehensive Cancer Center. She also serves as the Division Chief of GI Surgery and the Associate Chair of Research for the Department of Surgery. Dr. Simeone is the past-President of the Society of University Surgeons. Dr. Simeone's clinical interest is the surgical treatment of pancreatic diseases. Dr. Simeone has an NIH-funded laboratory with a focus on the molecular mechanisms of pancreatic tumorigenesis. 


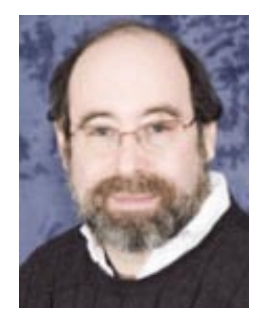

David M. Lubman is currently the Maude T. Lane Professor of Surgery at the University of Michigan Medical Center. He is also a professor of Pathology, a professor of Chemistry, an associate member of the Comprehensive Cancer Center, and an associate member of the BioInformatics Program. He received his AB from Cornell University in 1975 and his PhD in 1979 under the direction of Professor Richard N. Zare at Stanford University in Physical Chemistry. He was a fellow at the Weizmann Institute in 1981 in the Department of Chemical Physics. He has been at the University of Michigan since 1983 initially in the Department of Chemistry where he developed a program in the areas of laser chemistry and mass spectrometry. His lab has published over 235 articles and graduated $56 \mathrm{PhDs}$ many of whom have gone on to hold leadership positions in the pharmaceutical and biotech industries. Most recently, he has undergone a career switch and joined the Department of Surgery to develop a program in new technologies aimed at discovering markers of early cancer and prognosis of disease. Much of this work is focused in on glycoproteomic changes in proteins during cancer progression and newer work on mapping pathways in disease using a mass spec-based approach. The group has filed numerous patents resulting in the development of new companies and new products involved in liquid mapping of proteins, protein microarrays, and new mass spec-based technology and hardware. Dr. Lubman is a fellow of the American Association for the Advancement of Science and a member of the American Association of Cancer Research. 